\title{
Betting your life: an argument against certain advance directives
}

\author{
Christopher James Ryan Department of Psychiatry, Westmead Hospital, NSW, Australia
}

\begin{abstract}
In the last decade the use of advance directives or living wills has become increasingly common. This paper is concerned with those advance directives in which the user opts for withdrawal of active treatment in a future situation where he or she is incompetent to consent to conservative management but where that incompetence is potentially reversible. This type of directive assumes that the individual is able accurately to determine the type of treatment he or she would have adopted had he or she been competent in this future scenario. The paper argues that this assumption is flawed and provides theoretical and empirical evidence for this. If the assumption is false, and those taking out advance directives do not realise this, then the ethical bases for the use of these advance directives - the maximisation of the individual's autonomy and minimisation of harm are undermined. The paper concludes that this form of advance directive should be abolished.
\end{abstract}

A long time ago, in a country far far away, there lived a very wise old king. The king was a very ethical man and his subjects were very happy. Everyone lived together in perfect harmony and times were generally regarded as good.

One day the king introduced a new law. The law allowed his subjects to enter into a mysterious wager. Those who won the wager would receive a rich reward, but those who lost would be put to death. Entry into the wager was entirely voluntary and despite the dire consequences of losing many took up the challenge. To win, a contestant had only correctly to answer an apparently straightforward question. The question was known to all participants before they entered and all who took up the challenge were sure that they knew the answer and could not lose. Strangely, even the king's ethicists had no objection to the introduction of the law and in fact praised the king for his wisdom and progressiveness. The ethicists also believed that the answer to the question was obvious and focused only on the rich reward.

\section{Key words}

Living will; autonomy; utilitarianism; denial; palliative care; euthanasia.
Unfortunately, however, many contestants got the answer wrong. They lost the wager and were put to an early and needless death. The question, that caused so much difficulty, was this: "Even though you are now well and healthy, imagine yourself in a situation where you have a terminal illness and are temporarily confused or unconscious. Imagine that whilst you are in this state your doctors give you a choice; either they will treat you to the best of their ability and you may recover some of your health for some undefined period, or they will treat you conservatively and, though they will ensure that you are in no pain, they will not attempt to save your life. If you were in this situation what would you want the doctors to do?"

Advance directives or living wills frequently require their users to undertake the kind of task set out above; that is, to imagine themselves in a situation where they are required to make a decision about whether or not they should receive active treatment but are incompetent to do so. These have become increasingly popular over the last decade. Legislation giving statutory status to these directives has been enacted in many parts of the Western world and planned in many others. In places where no such legislation exists living wills are thought to have increasing weight in common law..$^{1-3}$

In this paper I oppose a common form of advance directive on ethical grounds. The basis of my argument is my contention that, like the citizens of the country above, many people who take out advance directives do so under the belief that they know the answer to the question above, when in fact they do not. In order support my position I will first provide evidence which supports this contention and then demonstrate the ethical difficulties this creates for advocates of living wills.

I do not intend to provide opposition to all forms of advance directive, but will restrict my discussion to a fairly narrow but not uncommon set of criteria. I will examine only cases where an advance directive demands that the user receive only conservative or palliative care in a situation where he or she is incompetent to consent to such treatment but where that incompetence is potentially reversible. 


\section{Getting the answer wrong}

My argument hinges on the notion that people are likely grossly to under-estimate their desire to have medical intervention should they become ill; I will therefore explain why this is likely to be so on theoretical grounds and then provide some empirical evidence that suggests that this actually occurs.

Denial is a strong and largely successful mechanism for dealing with the stressors of everyday life. For the healthy person considering a terminal illness it involves the subconscious decision to reject the possibility that one will suffer in the way one might be expected to if one were to succumb to such an illness. There are two standard ways of going about this. The first is simply to tell yourself that terminal illnesses are things that happen to other people and that they will not happen to you. This method works reasonably well whilst one is still young and all, or most, of the people that get such illnesses are not like you at all. It starts to lose its power, however, as you grow older and terminal illnesses begin to befall your peers. Now the other people begin to look a lot like you and the only-happens-to-others strategy looks increasingly anaemic.

The second option is to use denial in a slightly more complicated manner and when confronted by the suffering of another in the midst of a terminal illness to say that this would not happen to you because, if you were in that situation, you would kill yourself before the suffering became too great. Here you have traded the real and very distressing possibility that you may develop, and suffer at the hands of, a terminal illness for the hypothetical notion of a future early death. As a hypothetical abstract your early death is unpleasant but much more bearable than the realisation that you could become so ill.

Of course once you have developed a terminal illness, this coping strategy will no longer be successful. Now the possibility of your death is no longer hypothetical and you are faced with balancing real dying with the possibility of real suffering. While there is no doubt that some individuals now decide that they would still be better off dead, I believe that the vast majority of people now decide to battle it out. Most people with terminal illnesses do not want to die and are prepared to put up with a certain amount of suffering in order to live a little longer. Now that death is no longer a hypothetical it holds little appeal and frequently denial is used again, this time to maintain hope that a cure will be found. ${ }^{4}$

Human beings are, I suggest, very poor at determining their attitudes to treatment for some hypothetical future terminal illness and very frequently grossly under-estimate their future desire to go on living.

Though based on psychological theorising, there is some evidence to support this contention. The first piece of evidence is admittedly anecdotal but none the less quite powerful. Healthy people frequently believe that if they were suffering a terminal illness and required various forms of medical intervention they would rather be allowed to slip away. This view is so common among healthy people that it can be regarded as perfectly normal. Among terminally ill people, however, the sustained expression of a preference not to receive treatment is very rare. Most palliative care specialists will readily recall one or two patients who persistently requested that they be allowed to die. Some will recall several. However, palliative care physicians do no report that this sustained desire is very common and certainly do not report that it is the norm. This strongly suggests that many people who, when healthy, predict they would refuse treatment in the future, will change their mind when they develop a terminal illness.

This anecdotal evidence is supported by a number of studies in the psychiatric literature. One such study by Owen et al found that among patients with cancer the strongest interest in euthanasia was among those patients being offered potentially curative treatment. Patients with poorer prognoses, who were only being offered palliative care, tended to reject the idea of euthanasia as a future option $(\mathrm{p}<0.05) .{ }^{5}$ Similarly, a 1994 study by Danis et al, which examined the stability of future treatment preferences, found that while preferences for most remained stable over the study's two-year duration, people that had been hospitalised, had an accident or had become immobile were likely to change their health care preferences to opt for more intervention. ${ }^{6}$ Both studies suggest that having had an episode of serious illness or a deterioration of an existing illness may make people more likely to want more intervention.

Seale and Addington-Hall asked relatives and friends of people who had died whether the dead person would have benefited from an earlier death. They found that respondents, who were not spouses, were frequently willing to say that an earlier death would have been better for the person even though the person who had died had not expressed a desire to die sooner. That is, the healthy relatives and friends were keener on euthanasia than the terminally ill patient had been. This again suggests that healthy people may view euthanasia differently from terminally ill people or at least that it is hard to empathise with the position of the terminally ill. ${ }^{\text {? }}$

Though it is not possible directly to equate suicide with a desire for euthanasia, one might expect that if terminally ill people increasingly wanted to die as they became sicker and sicker then suicide among patients with terminal illness would peak towards the end of their illnesses. This would be the time when pain and suffering was at its worst and when there was little to look forward to. In fact, however, completed suicide is most common in the first year after diagnosis in the terminally ill. ${ }^{8}$ It may be that in this situation suicide more often represents an irrational reaction to the crisis of diagnosis than a reasoned decision that life has become intolerable. 
Further evidence that a desire for euthanasia is uncommon in the terminally ill comes from a study by Brown and co-workers who found that among forty-four terminally ill patients, the only patients who had experienced a desire for an early death were those who were suffering from a clinical depressive illness. ${ }^{9}$

\section{Arguments in support of advance directives}

Advocates of this form of advance directive argue for the documents along two lines. Firstly, they take a deontological position that the directives maximise the affected person's autonomy by allowing her some control over her medical management. They argue that since maximisation of autonomy is a legitimate aim and since living wills seem to facilitate the maximisation of autonomy, then living wills are not only ethically justified but beneficial. ${ }^{10-12}$ Second, advocates may take a utilitarian line and argue that the directives help to facilitate the death of people who believe they would be better off dead than alive. By facilitating these deaths the directives not only end people's suffering, but spare them an undignified death. In addition the directive may ease the burden on medical staff and family of the ill individual who may find making these decisions painful. Through all these means, they argue, the directive increases the net utility of the community. ${ }^{10}$

Opponents of this form of advance directive usually base their opposition upon an opposition to euthanasia. ${ }^{13}$ However, since most living will legislation throughout the world facilitates only passive euthanasia and since passive euthanasia is rarely objected to, there has been little solid opposition to this form of advance directive legislation.

My objections to these advance directives do not rely on an objection to either active or passive euthanasia. Rather my objections are based on the proposition that these living wills do not necessarily increase the user's autonomy nor society's net utility in the unproblematic way they are imagined to do, because people are much more likely to refuse treatment when faced with a future hypothetical scenario than when faced with a real here and now choice. If this contention is accepted it has a number of consequences for arguments used in support of living wills.

\section{Consequences for the argument from autonomy}

The principle of a right to autonomy holds that adult human beings have the right to make decisions about their lives and so direct the course of their own fate. The right to autonomy is a powerful maxim. It is the right to autonomy that underlies the notions of consent, the right to freedom and democracy itself. By grounding their support for directives in this principle proponents of living wills set up a strong case.

It is an accepted part of the principle, however, that one cannot properly exercise one's autonomy if one is not in possession of all available information that might influence one's decisions. A patient's consent to a procedure, for example, is only valid if she has been informed of all the risks and consequences. If the psychological reasoning and empirical evidence above is accepted, then a person currently using a living will does not have access to a vital piece of information that may radically alter her decision. Specifically, she does not know that it is highly likely that her decision, made now, that she would rather die if faced with a hypothetical future scenario is not what her decision would have been if she were actually faced with that scenario.

Almost everyone assumes that he knows his own mind and that he would know the choices he would make in the event of a crisis. While there is little doubt that the individual alone is in the best position to know how he would act and it is also true that some people must correctly guess how they would act, nevertheless evidence strongly suggests that many people simply get it wrong. They believe they would not opt for treatment in a hypothetical future circumstance but were they actually to face the circumstance they would opt for treatment. Most people have no experience of their reactions to a lifethreatening illness, they can only guess at their reaction and they frequently guess wrong. More importantly for my argument, people do not believe in, or even know of the possibility of, an inaccurate guess. If users of advance directives do not know of the distinct possibility that their choices may be inaccurate, they lack a vital piece of information and that lack prohibits a fully informed and autonomous choice.

\section{Consequences for the utilitarian argument}

The possibility that a large number of people are dying when they would not have wanted to because of the introduction of advance directives, directly threatens the utilitarian argument offered in support of these directives.

The utilitarian argument draws its strength from the hope that the existence of advance directives will end the suffering of people with terminal illnesses who have decided that they would be better off dead. It is assumed that they have come to this opinion by weighing up the benefits of their continued existence with the pain and suffering of their terminal illness. There is an additional hidden assumption that the affected individuals can accurately estimate this balance from the safety of health and happiness prior to their illness. If this additional assumption is unjustified then the utilitarian argument is undermined. 


\section{Conclusions regarding living wills}

With the argument from autonomy and the utilitarian argument both undermined, ethical support for living wills of this sort is seriously diminished. The effect this diminution will have upon one's attitudes to living wills will depend on both the seriousness with which one takes the evidence for the inaccuracy of people's choices and one's beliefs about how well this inaccuracy can be addressed through changes to legislation and education.

At a minimum one should require significant changes in legislation to address users' ignorance of their likelihood of wrong decisions. The principle of autonomy demands that the individual making the choice be given all available relevant information, therefore those making living wills must be informed of the apparent likelihood that their decision to refuse treatment now may not accurately reflect the decision they would make in the future, were they competent at the time. To my knowledge, no piece of living will legislation currently refers to this likelihood. Though there are numerous published advance directive forms and more publications to assist in filling them in, none of them inform the potential user of the likely inaccuracy of their current decision. ${ }^{10} 111415$

While such a change may satisfy strong advocates of advance directives that autonomy is now again maximised, I would remain dubious that this were the case. The logistics of giving such warnings to all people filling in living wills will necessarily mean that the warnings will be scant and superficial. The belief that one knows one's own mind now and in the future is understandably held with some vehemence by most of the community. The psychological needs met by the belief that one would rather be dead in a future tragic situation are strong and deeply ingrained. An insignificant warning is unlikely to have any impact upon this belief and many people will continue falsely to believe they definitely know what they would want in the hypothetical scenario.

This kind of reasoning leads me to believe that it will be practically impossible to allow people to make an autonomous choice about this kind of advance directive and therefore on the grounds that such directives will neither increase autonomy nor increase the community's level of utility I believe that this type of living will should be abolished.

It is important to note that this line of argument will not demand the abandonment of all varieties of advance directive. It will not, for example, apply to advance directives where the ability to consent to treatment is irreversibly lost. In this situation there will be no possibility of the person recovering to give carers a more accurate report of her current desire for treatment. Carers would then be justified in taking their best guess as to the affected individual's preferences, no matter how inaccurate it is likely to be. Moreover, this best guess will be substantially improved if the person has taken out a living will Neither will it affect advance directives made by people who are already critically ill and who are, for example, giving instruction that they should not be resuscitated in the event of cardiac arrest. These people are already critically ill and therefore are able correctly to determine their preferences for what is essentially their current situation.

The argument applies only to advance directives made by essentially healthy individuals who opt for withdrawal of active care in a situation where their inability to consent is potentially reversible. In these situations, patients should be resuscitated and their opinions regarding future treatment sought again now that they are in the scenario that they had previously only imagined. For some no doubt this will lead to considerable hardship, as they must again state their preference that they would rather be allowed to die, but for others, perhaps the majority, it will provide a safety net and a chance to reconsider their decision with all available information.

Those who would have wished to see the King's wager abolished because of the needless deaths it seemed to cause must be similarly troubled by this form of living will.

Christopher fames Ryan, MBBS, FRANZCP, is Consultant-Liaison Psychiatrist, Department of Psychiatry, Westmead Hospital, Westmead, New South Wales, Australia.

\section{References}

1 Mendelson D. The Medical Treatment (Enduring Power of Attorney) Act and assisted suicide: the legal position in Victoria. Bioethics News 1993; 12: 34-42.

2 Stern K. Living wills in English law. Palliative Medicine 1993; 7: 283-8.

3 Greco PJ, Schulman KA, Lavizzo-Mourey R, HansenFlaschen J. The Patient Self-Determination Act and the future of advance directives. Annals of Internal Medicine 1991; 115: 639-43.

4 Kübler-Ross E. On death and dying. New York: Macmillan, 1969.

5 Owen C, Tennant C, Levis J, Jones $M$. Suicide and euthanasia: patient attitudes in the context of cancer. Psycho-Oncology 1992; 1: 79-88.

6 Danis M, Garrett J, Harris R, Patrick DL. Stability of choices about life-sustaining treatments. Annals of Internal Medicine 1994; 120: 567-73.

7 Dillner L. Relatives keener on euthanasia than patients. British Medical fournal 1994; 309: 1107.

8 Allebeck P, Bolund C, Ringback G. Increased suicide rate in cancer patients. Fournal of Clinical Epidemiology 1980; 42: 611-6.

9 Brown JH, Henteleff P, Barakat S, Rowe CJ. Is it $\stackrel{\mathbb{Q}}{\varrho}$ normal for terminally ill patients to desire death? American fournal of Psychiatry 1986; 143: 208-11.

10 Molloy W, Mepham V, Clarnette R. Let me decide. Melbourne: Penguin, 1993.

11 Quill TE. Death and dignity. Making choices and taking charge. New York: WW Norton, 1993. 
12 Charlesworth M. A good death. In: Kuhse $\mathrm{H}$, ed. Willing to listen - waiting to die. Melbourne: Penguin, 1994: 203-16.

13 Marker R. Deadly compassion. The death of Ann Humphry and the case against euthanasia. London:
Harper Collins, 1994.

14 Humphry D. Dying with dignity: understanding euthanasia. New York: Birch Lane Press, 1992.

15 Kennedy L. Euthanasia. London: Chatto \& Windus, 1990.

News and notes

\section{UK's Muslim Law Council approves organ transplants}

The council, which consists of scholars from all the major Muslim schools of law in the UK, together with three distinguished lawyers, has considered the issue of organ transplantation and has made a statement that reflects the council's resolutions. The statement has been agreed by Sunni as well as Shia scholars. It is signed by M A Zaki Badawi, Chairman of The Muslim Law (Shariah) Council.

It is important to note the following principles of Islamic jurisprudence. The council points out:

1. A person has the legal authority over his own body, attested by the fact that he can hire himself for work which might be difficult or exhausting. He may also volunteer for war which may expose him to death.

2. A person is forbidden from harming himself or others. (It is not legitimate in Islam to inflict harm on others or to suffer harm from them - Haddith).

3. In case of necessity, certain prohibitions are waived, as when the life of a person is threatened by the prohibition on eating carrion or drinking wine.

4. Confronted with two evils a person is permitted to choose the lesser of the two, as in the case of a starving person whose life could be saved by either eating carrion or stealing from another person's food. He would be permitted to opt for the latter.

5. Islam made it an obligation upon the sick to seek treatment.
In the light of these principles, and after thorough consideration "regarding medical opinion and several edicts issued by different religious bodies", the council has resolved that:

- The medical profession is the proper authority to define the signs of death.

- Current medical knowledge considers brain stem death to be a proper definition of death.

- The council accepts brain stem death as constituting the end of life for the purpose of organ transplant.

- The council supports organ transplant as a means of alleviating pain or saving life on the basis of the rules of Shariah.

- Muslims may carry donor cards.

- The next of kin of a dead person, in the absence of a donor card or an expressed wish of the dead person to donate his organs, may give permission to obtain organs from the body to save other people's lives.

- Organ donation must be given freely without reward. Trading in organs is prohibited.

More information may be obtained from: The Muslim Law (Shariah) Council, 20-22 Creffield Road, London, W5 3RP. Tel: +44-81-992-6636 - Fax: +44-81-993-3946. 